\title{
Utilizing The Social Transaction Theory Of Social Ontology To Understand Organizational Culture Change
}

Thomas B. Whalen, McPherson College, USA

\begin{abstract}
Recent popular literature has spawned an ever increasing amount of leadership and management advice on how to manage, lead, and institute organizational change. While some of this advice may be effective, the literature has shown that the majority of organizational change initiatives fail. Most current leadership and management practices prescribe organizational treatment without understanding the nature and underlying cause of organizational illness. In the case of organizational culture, failure to properly institute change can have long-term repercussions. This paper proposes that the social transaction theory of social ontology can be used to explain not only how organizational culture is formed, but also how it responds to attempts to change it. Thus, by understanding the underlying mechanisms of culture formation and transformation, effective approaches can be developed to demonstrate how lasting change can be instituted.
\end{abstract}

Keywords: Organizational Culture Change; Social Ontology; Social Transaction Theory; Leadership; Management

\section{INTRODUCTION}

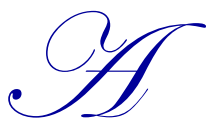

fashionable topic in the management and leadership literature has been how to manage and change organizational culture. A popular schema argues that a leader establishes and maintains an organization's culture (Kotter \& Heskett, 1992; Schein, 1985/2004). When it comes time for the culture to change, the argument continues, it is the leader's responsibility to change it. Unfortunately, the culture rarely ever changes in the desired manner and the leader is blamed for poor leadership and the inability to change the culture. The leader's reputation is often damaged and increased distrust of management is possible. Strebel (1996) observed that culture change initiatives had a success rate below 50\%. Beer and Nohria (2000) were more specific and reported that $70 \%$ of change initiatives fail. Finally, Cameron and Quinn (2011) placed the success rate at between 20 and $60 \%$ citing three different studies. Given the plethora of books by championship winning coaches, military leaders, corporate executives, and other leadership sages promoting their formula for changing organizational culture, one would think that these formulas have a firm theoretical grounding and thus a high probability of success. Nevertheless, an extensive literature review revealed that typically an author's life experience, rather than a theoretical grounding, is the basis for the formula.

This paper will argue that the problem underlying change initiative failure is more frequently not the change initiation methodology, but rather the lack of understanding of how organizational culture forms and then continually adapts to changing circumstances. To use an engineering term, no one has arrived at the root cause to understand the underlying mechanism of culture change failure. This paper will present the social transaction theory of social ontology (Whalen, 2011, 2012) in an effort to remedy this deficiency. The hope is that if leaders and managers understand the mechanisms underlying cultural formation and adaptation, then strategies can be developed, evaluated, and selected so that change initiatives can have a higher success rate.

\section{DEFINING ORGANIZATIONAL CULTURE}

The concept of organizational culture is relatively new. In 1972, Roger Harrison first posited that organizations have culture that can be identified, categorized, and managed (Cartwright \& Cooper, 1992, p. 63). 
This idea quickly gained traction and there was increased research into organizational culture. Davis (1984) coined the term "corporate culture" in the mid-70s. Pettigrew (1979) focused on organizational culture. Given the success of the Japanese automobile industry and the theory that it was due to organizational culture, a trend began in both the academy and the business world to examine the concept (Kotter \& Heskett, 1992). Schein (1985/2004) attributed organizational culture to leadership and identified the leader as the primary factor in cultural formation. Eventually, academics and business researchers began to explore how to manipulate culture. In 2013, a literature review was conducted to study this phenomenon. The review identified 224 books and articles published since 1980 that have advocated various methods for changing organizational culture. Nevertheless, given the poor overall success rate and efficacy, the underlying mechanism of these methods may need to be reevaluated.

This paper will focus on organizational culture, but it should be noted that all elements of society, including those of the social structures, institutions, and systems; legal, political, and economic systems will fall under this theoretical explanation. Four sources are used in defining organizational culture, which provide the reader with diverse, but supporting, opinions and present a common theme. Pettigrew (1979) identified organizational culture as a "system of such publicly and collectively accepted meanings operating for a given group at a given time" (p. 574). Deal and Kennedy (1982/2000) more succinctly described it as, "The way we do things around here" (p. 4). Davis (1984) focused on corporate culture and defined it as, "the pattern of shared beliefs and values that give members of an institution meaning and provide them with the rules for behavior in their organization" (p. 1). Finally, Ogbonna and Harris (2002) defined organizational culture as, "the collective sum of beliefs, values, meanings, and assumptions that are shared by a social group and that help to shape the ways in which they respond to each other and to their external environment" (p. 34). Now that a working understanding of what organizational culture has been established, how it is formed will be examined.

\section{THE SOCIAL TRANSACTION THEORY OF SOCIAL ONTOLOGY}

Although there have been many theories of social and cultural ontology, this paper will utilize Whalen's $(2011,2012)$ transdisciplinary theory of social ontology. This theory combined major elements from complexity science (Axelrod \& Cohen, 2000; Holland, 1995), George Hebert Mead's (1934/1967) social interaction theory, Dewey and Bentley's (1949) transactional strategy, Strauss' (1978) negotiated order theory, and added minor elements from Giddens' (1979) structuration theory, Bruner's (1990) folk psychology, and Ricoeur's (1976) interpretation theory.

The basic building block of social transaction theory is the complex adaptive system (Axelrod \& Cohen, 2000; Holland, 1995). This model has three essential elements. First, agents that have local knowledge interact with each other and engage in a decision-making process. Second, the results of this process have both positive and negative outcomes. Finally, the outcome is evaluated so that agents can base future decisions on past results. A set of rules and strategies eventually emerge from the continual exercise of this process. The complex adaptive model is problematic in that it relies on the mechanisms of independent agents and their contingent interaction. Parsons (1937) called this mechanism a "unit act." Nevertheless, he eventually rejected it in a later work due to the theoretical problem of "the 'double contingency' of the process of interaction" (Parsons, 1951, p. 36). Essentially, the resolution of two independent actions is contingent on the independent decisions of two actors rather than the dependent outcome of an interacting dyad. By replacing independent agents with Mead's (1934/1967) interacting dyad, the issue is resolved. This change brings his work more in line with complexity science. Mead also theorized that it was only through social interaction that mind, self, and society emerged.

Although dyadic interaction is an essential element, Dewey and Bentley (1949) observed that people do not interact in a vacuum. Rather, interaction takes place within an environment and is influenced by individuals beyond the dyad. Any social interaction is influenced by the environment and social constructions. Thus, social interaction on a street corner in New York City may take on a completely different flavor than social interaction in a Kansas wheat field. The physical and social environment and their associated impact cannot be ignored. Following Dewey and Bentley, social interaction is modified to social transaction in the complex adaptive system.

The final major element is negotiated order theory. Strauss (1978) argued that "social order was negotiated order" (p. 5). Gerson (1976) extended Strauss' earlier work and observed that "smaller scale negotiations are 
continually taking place in very large numbers within the context of the larger scale arrangements which are changing more slowly and less visibly to participants" (p. 796). Day and Day (1977) theorized that all negotiated agreements are continually being renegotiated and "are always subject to change" (p. 131). Social transaction theory combines the social transaction elements of Mead, and Dewey and Bentley with the position that underlying every transaction there is also an element of negotiation and renegotiation (Whalen, 2012). Thus, negotiation is embedded in every transaction and is a continuous occurrence.

Whalen $(2011,2012)$ theorized that "our social fabric is continually emerging from this combination of social transaction and negotiation. It is from our transactions/negotiations that society, culture, and economy emerge. Thus, social convention and structure are not monolithic entities imposed on society, but rather they emerge from our continual social transaction and the often subtle negotiations which underlie each transaction." Building on Giddens' (1979) structuration theory, Whalen (2012) argued that "Without the continued transaction of interdependent agents, social structures cease to exist" (p. 26). For purposes of this paper, it is important to focus on the phrase, "the continued transaction of interdependent agents." As noted above, managers and leaders typically ignore this idea and focus on themselves as an independent agent causing change within an organization. Instead, they need to think of themselves as a part of the continuous transaction/negotiation process that takes place within an organization.

Another important element is folk psychology (Bruner, 1990). Bruner theorized that people develop shared public meaning through narrative in response to non-canonical events. Whalen (2012) argued that it can be logically inferred that this meaning emerges from social transaction and the underlying negotiation. Thus, when a leader or manager introduces a change initiative, organizational members may see this act as a non-canonical event. The response is to develop a shared narrative that explains the change initiative. These emergent narratives become part of the organizational culture and therefore influence the "collective sum of beliefs, values, meanings, and assumptions' that Ogbonna and Harris (2002) described. A leader or manager may be able to control some of the narrative that emerges, but it is unlikely that all narrative can be controlled. Even if the change initiative is seen as expected and canonical, organizational members will transact/negotiate, a narrative will emerge, and organization members will collectively decide what the initiative means for themselves and the organization. Thus, the organization's collective response to the initiative may differ from what leadership and management expected.

\section{LEADERS, POWER, AND ORGANIZATIONAL CULTURE}

If social structure is being continually negotiated and renegotiated in the present, then the same applies to organizational culture and other social and economic issues for that matter. Each time members of an organization socially transact, the underlying negotiation may implicitly or explicitly change the previously negotiated social order. Although culture may not noticeably change on an hourly or weekly basis, it can be argued that it is continually changing, although that change is most frequently very subtle or not even noticeable. Culture certainly changes as other changes are introduced to the organization. Changes can range from internal changes, such as new personnel, new assignments, new products and services, and new policies and procedures; to external changes, such as changing clientele, markets, competitors, or shifts in the business cycle. With each change, the individuals within the organization transact and negotiate what those changes mean to both themselves and the organization. The emergents from these transaction/negotiations may range from barely detectable to blatantly obvious. More importantly, leaders and managers take part in these negotiations whether they intend to or not. They are just as much a part of the social transaction from which culture emerges as any other member. The emphasis is intentional. Even though management expects that their organizational power and authority grants them significantly greater influence, most often that influence is limited in how well it can determine social outcomes within the organization. More often, the outcome can differ from the desired result through no fault of the change initiator.

Before continuing, the concepts of power and authority need to be addressed. Lukes (1974/2005) described power as, " $A$ exercises power over $B$ when $A$ affects $B$ in a manner contrary to $B$ 's interests" (p. 30). The concept of power must also take into consideration the potential for conflict of interest. Lukes asserted that actual, observable conflict is not necessary for the exercise of power, but only the perception of conflict. Power can be obtained by general consensus, by cultural norms and expectations, by perceived or actual force, violence, coercion, persuasion, or by the threat of sanctions. Lukes noted that the capacity of power need only be present. An individual does not 
necessarily need to exercise power to have power. Addressing the concept of authority, the Oxford English Dictionary defined authority as "the power or right to enforce obedience; the right to command, or give an ultimate decision" (Murray, Bradley, Craigie, \& Onions, 1978, Vol. 1, p. 572). Thus, the concept of authority assumes that power is present.

As noted above, there is a general view in the leadership and management literature that argues that leaders and managers can control and change organizational culture as necessary. There have been times that this control has taken on sinister aspects, such as the re-education programs that political dissidents were subjected to in the former Soviet Union (Solzhenitsyn, 1974) and Maoist China (Li, 2008), but generally control takes the form of wellintended actions initiated by organizational leaders. Many assume that the power and authority given to leaders and managers should be sufficient to ensure that effective change occurs. Nevertheless, as noted above, these change attempts are largely unsuccessful (Strebel, 1996; Beer \& Nohria, 2000; Cameron \& Quinn, 2011).

So why do change initiatives fail even though leaders and managers have the authority and power to initiate organizational culture change? This paper argues that the answer lies in how culture is formed and continually reformed. Social transaction theory posits that since culture is collectively created and recreated through transaction/negotiation, leaders and managers are only part of the formation and reformation process. Consider the number of transactions that occur in an organization on any given day. Organizational size and purpose directly influence that number. The number of transactions increases factorially with organization size and the number of outside contacts. The greater the number of transactions, the smaller the percentage of overall transactions in which the leader takes part. The larger the size of an organization, the smaller the percentage of transactions in which the leader/manager takes part, and thus the leader/manager has less influence on the collective narrative that emerges. Essentially, the bigger the organization, the harder it is to change the organizational culture. Granted, given their position of power, they may be the most influential member of the organization, but they are still just one member. Not even a totalitarian dictator can control every aspect of their rule. While they may exercise power and authority over the collective organization, it is the members of that organization (of which the leader/manager is only one part) that respond through continual transaction/negotiation, create the narrative that explains the change initiative, create the underlying meaning, and ultimately decide in which direction the organizational culture will move.

\section{A HYPOTHETICAL SCENARIO}

Imagine that an executive, Mr. Smith, has decided his organization's culture needs to change as part of a strategic initiative. He may use any number of methods presented in the literature to initiate this change. There are two extremes of possible executive action. The first extreme is that Mr. Smith simply communicates his initial change directive and does nothing further to communicate to the organizational members. The members hear of the directive and then, through normal transaction/negotiation, begin to create a narrative that explains the change initiative and how they respond to it. Here Mr. Smith is relying on the power and authority that is present in the initial directive to influence the narrative. $\mathrm{He}$ is absent from the thousands, perhaps millions, of transaction/negotiations that take place between organizational members. Although he may be exercising his power and authority, his influence in the continual transaction/negotiation process that occurs between members is negligible.

At the other extreme, Mr. Smith understands that his organization's culture is formed and reformed through the transactions/negotiations of its members. Therefore, he feels it is important to influence the collective narrative as frequently as possible and take part in as many transaction/negotiations as possible. This influence would take the form of various communications to the membership. Communication may be formal or informal, by just one individual or by the entire management team, be one-on-one or in a group setting. Perhaps, he engages in what is commonly called "management by walking around." Regardless of how he maximizes the number of transactions/negotiations that he takes part in, it is essential that Mr. Smith proactively influence the continual collective negotiation and renegotiation of the organization's beliefs, values, meanings, and assumptions. At this extreme, the initiative may still fail, but Mr. Smith has taken part in a substantially greater proportion of the overall transaction/negotiations from which the organizational narrative, meaning, and culture will emerge. Given this higher proportion of transaction and involvement, he has a greater probability of influencing the narrative and subsequent culture change toward his desired outcome. 
Comparing the two extremes, one might assume that the second, more proactive scenario would produce a greater number of positive outcomes. Nevertheless, one cannot make that assumption without actual documented studies. In the absence of such research, the leadership and management community is invited to critically examine the theoretical grounding of any change methodology they are contemplating.

\section{CONCLUSION AND FURTHER RESEARCH}

This paper has presented the social transaction theory of social ontology and how it can be used to explain why organizational change initiatives often fail. The theory argued that organizational culture is formed and continually reformed from the constant transaction and underlying negotiation present in human life. This paper posited that change initiatives which fail to take this formation mechanism into consideration will have a higher likelihood of failure. The leader or manager who wishes to have a greater chance at a successful change initiative should attempt to influence the narrative that emerges from the continual transaction/negotiation of organizational members.

This has been strictly a theoretical and hypothetical presentation. Since this theory has only recently been published, it has not yet been tested or practically applied. Further research is required to test the theory and its ramifications for change initiatives. Ideally, a meta-analysis of case studies addressing the topic would be an effective first step; however, any work toward theory validation or nullification would benefit the community.

\section{AUTHOR INFORMATION}

Dr. Thomas Brian Whalen is presently an assistant professor of business at McPherson College in McPherson, Kansas. He holds a Ph.D. in leadership studies from Gonzaga University in Spokane, Washington, a M.S. in management from Troy University in Alabama, and a B.S. in systems engineering from the U.S. Naval Academy in Maryland. Tom's academic interests include organizational behavior, culture studies, leadership studies, and business. E-mail: whalent@mcpherson.edu

\section{REFERENCES}

1. Axelrod, R., \& Cohen, M. D. (2000). Harnessing complexity: Organizational implications of a scientific frontier. New York, NY: Basic Books.

2. Beer, M., \& Nohria, N. (2000) Cracking the code of change. Harvard Business Review, 78(3), 133-141.

3. $\quad$ Bruner, J. S. (1990). Acts of meaning. Cambridge, MA: Harvard University Press.

4. Cameron, K. S., \& Quinn, R. E. (2011) Diagnosing and changing organizational culture: Based on the competing value framework ( $3^{\text {rd }}$ ed.). San Francisco, CA: John Wiley and Sons. (Originally published in 1999).

5. Cartwright, S., \& Cooper, G. L. (1992). Managing mergers and acquisitions: Integrating people and cultures. Oxford, UK: Butterworth-Heinemann.

6. $\quad$ Davis, S. M. (1984). Managing corporate culture. New York, NY: Harper \& Row.

7. Day, R., \& Day, J. V. (1977). A review of the current state of negotiated order theory: An appreciation and a critique. The Sociological Quarterly, 18(1), 126-142.

8. Deal, T. E., \& Kennedy, A. A. (2000). Corporate cultures: The rites and rituals of corporate life. New York, NY: Perseus Books. (Originally published in 1982).

9. Dewey, J., \& Bentley, A. F. (1949). Knowing and the known. Boston, MA: Beacon Press.

10. Gerson, E. M. (1976). On "quality of life". American Sociological Review, 41(5), 793-806.

11. Giddens, A. (1979). Central problems in social theory: Action, structure and contradiction in social analysis. Berkley, CA: University of California Press.

12. Holland, J. H. (1995). Hidden order: How adaptation builds complexity. Reading, MA: Helix Books.

13. Kotter, J. P., \& Heskett, J. L. (1992). Corporate culture and performance. New York, NY: The Free Press.

14. Li, C. N. (2008). The bitter sea: Coming of age in a China before Mao. New York, NY: Harper Collins.

15. Lukes, S. (2005). Power: A radical view ( $2^{\text {nd }}$ ed.). New York, NY: Palgrave Macmillan. (Originally published in 1974). 
16. Mead, G. H. (1967). Mind, self and society from the standpoint of a social behaviorist (C. W. Morris, Ed.). Chicago, IL: University of Chicago Press. (Originally published in 1934).

17. Murray, J. A. H., Bradley, H., Craigie, W. A., \& Onions, C. T. (Eds.). (1978). The Oxford English dictionary: Being a corrected re-issue with an introduction, supplement, and bibliography of a new English dictionary on historical principles, founded mainly on the materials collected by the Philological Society. Oxford, UK: Clarendon Press.

18. Ogbonna, E., \& Harris, L. C. (2002). Managing organisational culture: Insights from the hospitality industry. Human Resource Management Journal, 12(1), 33-53.

19. Parsons, T. (1937). The structure of social action: A study in social theory with special reference to a group of recent European writers. New York, NY: McGraw-Hill.

20. Parsons, T. (1951). The social system. New York, NY: The Free Press.

21. Pettigrew, A. (1979). On studying organizational cultures. Administrative Science Quarterly, 24(2), 570-81.

22. Ricoeur, P. (1976). Interpretation theory: Discourse and the surplus of meaning. Fort Worth, TX: The Texas Christian University Press.

23. Schein, E. H. (2004). Organizational culture and leadership ( $3^{\text {rd }}$ ed.). San Francisco, CA: Jossey-Bass. (Originally published in 1985).

24. Solzhenitsyn, A. I. (1974). The gulag archipelago 1918-1956: An experiment in literary investigation (3 vols., T. P. Whitney, Trans.). New York, NY: Harper \& Row.

25. Strauss, A. (1978). Negotiations: Varieties, contexts, and social order. San Francisco, CA: Jossey-Bass.

26. Strebel, P. (1996). Why do employees resist change? Harvard Business Review, 74(3), 86-92.

27. Whalen, T. B. (2011). Transaction, negotiation, and emergence: A theoretical refinement of general social theory. (Doctoral dissertation). Gonzaga University, Spokane, WA.

28. Whalen, T. B. (2012). A theory of social ontology: Explaining the emergence of society, culture, and economy. The International Journal of Interdisciplinary Cultural Studies, 7(1), 21-34. 